\title{
New focusing and dispersive planar component based on an optical phased array
}

Citation for published version (APA):

Smit, M. K. (1988). New focusing and dispersive planar component based on an optical phased array. Electronics Letters, 24(7), 385-386.

Document status and date:

Published: 01/01/1988

\section{Document Version:}

Publisher's PDF, also known as Version of Record (includes final page, issue and volume numbers)

\section{Please check the document version of this publication:}

- A submitted manuscript is the version of the article upon submission and before peer-review. There can be important differences between the submitted version and the official published version of record. People interested in the research are advised to contact the author for the final version of the publication, or visit the $\mathrm{DOI}$ to the publisher's website.

- The final author version and the galley proof are versions of the publication after peer review.

- The final published version features the final layout of the paper including the volume, issue and page numbers.

Link to publication

\section{General rights}

Copyright and moral rights for the publications made accessible in the public portal are retained by the authors and/or other copyright owners and it is a condition of accessing publications that users recognise and abide by the legal requirements associated with these rights.

- Users may download and print one copy of any publication from the public portal for the purpose of private study or research.

- You may not further distribute the material or use it for any profit-making activity or commercial gain

- You may freely distribute the URL identifying the publication in the public portal.

If the publication is distributed under the terms of Article 25fa of the Dutch Copyright Act, indicated by the "Taverne" license above, please follow below link for the End User Agreement:

www.tue.nl/taverne

Take down policy

If you believe that this document breaches copyright please contact us at:

openaccess@tue.nl

providing details and we will investigate your claim. 


\section{References}

1 For an updated overview see for example 'Proceedings of the International Conference on Science and Technology of Synthetic Metals ICSM '86', Synth. Met., 1987, 17-18

2 MAZUREK, H., DAY, D. R., MABY, E. W., ABEL, J. S., SENTURIA, S. D., DRESSELHAUS, M. S., and DRESSELhAUS, G.: 'Electrical properties of ion-implanted PPS', J. Polym. Sci. Polym. Phys. Ed., 1983, 21, pp. $537-551$

3 KOSHIDA, N., and WACH, Y.: 'Application of ion implantation for doping of polyacetylene films', Appl. Phys. Lett., 1984, 45, pp. 436-437

4 WADA, T., TAKENo, A., IWAKI, M., SASABE, H., and KOBAYASH, Y.: 'Fabrication of a stable $p-n$ junction in a polyacetylene film by ion implantation', J. Chem. Soc., 1985, pp. 1194-1195

5 KOVACIC, P., and KYRIAKIS, A.: 'Polymerization of benzene to ppolyphenyl by aluminum chloride cupric chloride', J. Am. Chem. Soc., 1963, 85, pp. 454-458

6 DUROUX, J. L., MOliton, A., FROYER, G., and MAURICE, F.: 'Caracteristiques diélectriques du polyparaphénylène', Eur. Polym. J., 1986, 22, pp. 439-442

7 DURoux, J. L.: Thesis 'Implantation ionique dans le PPP' (Université de Limoges, 1987)

\section{NEW FOCUSING AND DISPERSIVE PLANAR COMPONENT BASED ON AN OPTICAL PHASED ARRAY}

Indexing terms: Optics, Optical waveguide components, Optical multi/demultiplexers, Integrated optics

A novel focusing and dispersive component is presented which is based on a phased array of bent optical waveguides. It combines good optical properties with small dimensions and can be realised with (high-quality) optical lithography. Applications are (de)multiplexers, wavelength filters and polarisation splitters.

Introduction: Focusing and dispersive elements play an important role in integrated optical circuits. Components which combine both functions are of special interest for the spatial separation of signals with different wavelengths, as may occur in wavelength demultiplexers or wavelength filters.

Planar lenses are conceived and executed in many kinds and dimensions. Mode-index lenses are easily fabricated but are of poor quality and require high index contrasts to obtain subcentimetre focal lengths. Planar Luneberg lenses and geodetical lenses are of better quality but require a technology which is not suited for the mass production of integrated circuits. In addition, it is difficult to miniaturise them to any extent. ${ }^{1,2}$ Fresnel lenses combine small dimensions (millimetre-order) with reasonable quality. However, they require high index contrasts. ${ }^{3}$ All lenses of the above type are, in principle, nondispersive.

The only small sized component combining focusing and dispersive properties which can be realised with low optical contrast, is the curved planar grating. ${ }^{3}$ A disadvantage of the grating is that it cannot be realised with conventional optical lithography but requires submicron lithography (holographic or electron beam).

In the following, a novel component is proposed and demonstrated with properties comparable to a grating, which is realised, however, with conventional optical lithography.

Basic principle: If a broad parallel beam is impinging on an array of concentric planar optical waveguides, as shown in Fig. 1, part of the incident power will couple into the waveguides and the other part will propagate straight forward or be scattered.

The light coupled into the waveguides will propagate to the output plane and arrive there with phase distribution

$$
\phi_{i}=\beta \psi R_{i}+\phi_{0}
$$

in which $\beta$ is the propagation constant of the waveguide, $\phi_{0}$ is the phase at the input plane and is not relevant for the follow- ing, $\psi$ is the sector angle of the concentric array, and $R_{i}$ is the bending radius of the $i$ th waveguide

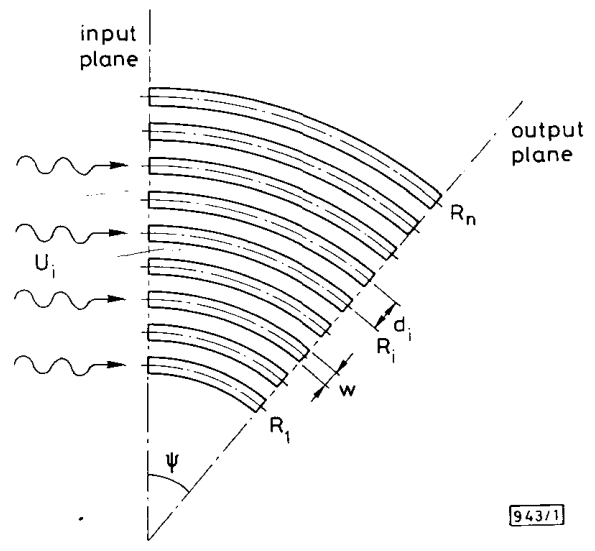

Fig. 1 Phased array geometry

If we choose the concentric waveguides not equidistant, but such that:

$$
\beta \psi R_{i}=2 \pi m_{i}
$$

in which $m_{i}$ are integers, then the array will behave like a phased array with uniform phase distribution. If $m_{i}-m_{i-1}=$ 10 , for example, then phase variations between $-\pi$ and $+\pi$ can be obtained by varying the mutual distance $\Delta R_{i}=R_{i}$ $-R_{i-1}$ between plus or minus $5 \%$, so that the array is only slightly different from an equidistant array.

The phase distribution need not necessarily be uniform; each required distribution is realised equally well by computing the $R_{i}$ from:

$$
\beta \psi R_{i}=\Phi\left(R_{i}\right)+2 \pi m_{i}
$$

in which $\Phi\left(R_{i}\right)$ is the required phase distribution and the $m_{i}$ are chosen such that the equidistant array is approximated as closely as possible. A quadratic distribution will yield a focusing operation. The phased array is principally dispersive. The channel length is proportional to $R_{i}$ so that a frequency shift $d f$ will cause a phase shift which is linear in $R_{i}$. Consequently, the position of the focus in the focal plane will shift linearly with $d f$, the focal length remaining unaffected.

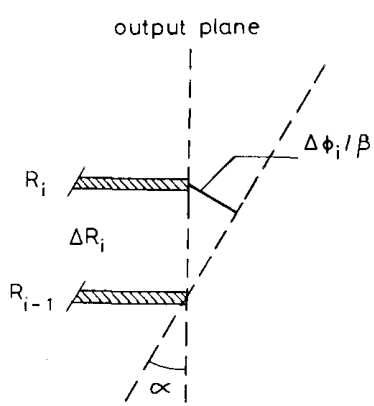

Fig. 2 Relation between the wavefront tilting angle $\alpha$ and the phase difference $\Delta \phi_{i}$

The dispersion is easily inferred from Fig. 2. For small values of $\alpha$ the dispersion angle $d \alpha$ follows

$$
d \alpha \simeq \frac{d \beta \psi \Delta R_{i} / \beta}{\Delta R_{i}}=\psi \frac{d \beta}{\beta}
$$

which means that a wavelength shift of $1 \%$ will cause an angular dispersion of $0.01 \psi$; with $\psi=\pi$ this is roughly $2^{\circ}$.

Experimental realisation: We realised a set of arrays using $\mathrm{Al}_{2} \mathrm{O}_{3}$ ridge guides on a silicon substrate, as described in References 4 and 5. Fig. 3 shows a photograph of the experi- 
mental configuration. The substrate comprises five identical arrays (the white areas). We chose a number of 31 concentric waveguides with a width of $3 \mu \mathrm{m}$ at an average distance $\overline{\Delta R_{i}}$ of $6 \mu \mathrm{m}, R_{i}$ varying between 910 and $1090 \mu \mathrm{m}$. $\psi$ was chosen $30^{\circ}$.

A phased array having different orders and multiple foci will occur without additional measures. The photograph shows a number of focused beams emerging from the second array, which is excited with a broad Gaussian $\mathrm{He}-\mathrm{Ne}$ beam $(\lambda=0.6320 \mu \mathrm{m})$. The dashed line represents the design position for the focal plane $(f=1 \mathrm{~mm})$. The spatial separation of the orders in the focal plane compares well with the theoretically expected value $(66 \mu \mathrm{m})$.

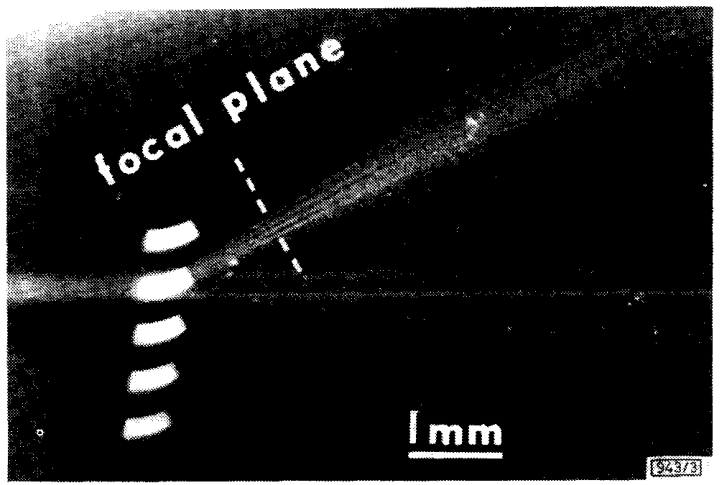

Fig. 3 Focusing phased array showing multiple orders

To avoid the occurrence of multiple orders, and simultaneously reduce coupling losses, the array should be provided with fan-in and fan-out coupling sections. The dispersion of this component can be utilised for spatially separating a number of wavelengths by positioning a set of receiver waveguides next to each other in the focal plane. We realised a small size $(1.3 \times 4 \mathrm{~mm})$ five-channel demultiplexer prototype working at $\mathrm{He}-\mathrm{Ne}$ wavelength with a wavelength channel spacing of $0.5 \%$, exhibiting good focusing properties and a channel separation better than $20 \mathrm{~dB}$.

Conclusions: A novel focusing and dispersive element is introduced and demonstrated which has properties and dimensions comparable to a curved planar grating, but can be realised with conventional (high quality) optical lithography. Applications are small wavelength (de)multiplexers, polarisation splitters and wavelength filters.

\section{K. SMIT}

2nd February 1988

Laboratory of Telecommunication \& Remote Sensing Technology

Faculty of Electrical Engineering

Delft University of Technology

PO Box 5031, 2600 GA Delft, The Netherlands

\section{References}

1 ANDERSON, D. B., DAVIS, R. L., BoYD, J. T., and AUGuST, R. R.: 'Comparison of optical-waveguide lens technologies', IEEE J. Quantum Electron., 1977, QE-13, pp. 275-282

2 hatakoshI, G., INOUE, H., NAITO, K., UMEGAKI, S., and TANAKA, S. 'Optical waveguide lenses', Opt. Acta, 1979, 26, pp. 961-968

3 SUHARA, T., and NISHIHARA, H.: 'Integrated optics components and devices using periodic structures', IEEE J. Quantum Electron., 1986, QE-22, pp. 845-867

4 SMIT, M. K., VAN DER LAAN, C. J., and ACKET, G. A.: ' $\mathrm{Al}_{2} \mathrm{O}_{3}$-films for integrated optics', Thin Solid Films, 1986, 138, pp. 171-181

5 SMIT, M. K.: 'Sputtered planar optical waveguides'. Sensors \& Actuators, Procs. S\&A Symposium of the Twente University of Technology, Enschede, The Netherlands, October 30-31, 1986, pp. 45-55

\section{ACCURATE PATTERN SYNTHESIS OF \\ PARALLEL DIPOLE ARRAYS AND ITS APPLICATION TO UNEQUAL ELEMENTS}

Indexing terms: Antennas, Dipole antennas, Antenna radiation patterns, Antenna arrays

A new simple method for accurate radiation pattern synthesis of parallel dipole arrays is described and its applications to low-sidelobe arrays with equal and unequal elements are presented.

Introduction: In antenna arrays, the distributions of field sources on elements are different, and this can cause significant errors in the resulting radiation patterns if the classical synthesis theory of point sources is used.,2 Some authors have proposed methods based on the method of moments and obtained good results, ${ }^{2,3}$ but all these methods must make use of the $\delta$-excitation model to approximate the fields produced by the driving voltages. However, they are all confined to relatively small arrays by computer capacity, so the problem of precise pattern synthesis remains.

The method proposed in this letter does not follow the procedure of the method of moments directly. By some assumptions based on physical considerations about mutual coupling, Pocklington's integral equation is transformed into equations involving the current flowing in only one element in an array. One can obtain the required driving voltages and the input impedances of all the dipoles by solving the equations numerically element by element. As an example, a linear array of parallel dipoles with equal length is synthesised and we show that the lengths of dipoles can be modified easily in this method to satisfy some requirements of input power distributions.

Method: Consider an $N$-element linear array of parallel dipoles in free space. The elements are of the same size and the axes of dipoles are perpendicular to that of the array. Obviously, the contribution of the $n$th element to the $H$-plane pattern is

$$
I_{n}=\int i_{n}\left(x_{n}\right) d x_{n} \quad n=1,2, \ldots, N
$$

where $x_{n}$ is the co-ordinate along element $n$ and $i_{n}$ is the current distribution on it. The limit of the integration is the whole length of the dipole. Then the problem becomes looking for $[V]=\left[V_{1}, V_{2}, \ldots, V_{N}\right]$ under which the array produces the pattern defined by $[I]=\left[I_{1}, I_{2}, \ldots, I_{N}\right] . V_{n}$ is the required driving voltage of dipole $n$ and $[I]$ can be any distribution resulting from the classical point source theory.

For this array, Pocklington's integral equation for the current distributions of the $N$ elements is

$$
\begin{array}{r}
-j \omega \mu \sum_{n=1}^{N} \int i_{n}\left(x_{n}^{\prime}\left[1+\frac{1}{k^{2}} \cdot \frac{d^{2}}{d x_{m}^{2}}\right] \cdot g \cdot d x_{n}^{\prime}=-f\left(x_{m}\right) \cdot V_{m}\right. \\
m=1,2, \ldots, N
\end{array}
$$

where $f$ is the impressed field at points on element $m$ produced by a unit driving voltage terminated at the dipole. $g$ is Green's function between $x_{m}$ and $x_{n}^{\prime}$.

To obtain a tractable formulation, certain assumptions are made on the basis of mutual coupling:

(a) The laws of current distribution of nearby elements are similar in an array. The amplitude and phase vary.

(b) The effect of one element on another is mainly determined by its current integral. A small change in current distribution does not change the effect if the integral is definite.

(c) Strong mutual coupling exists only between nearby elements.

Consider now the $N C$ th element which is near the centre of the array. Following the assumptions above

$$
i_{n}\left(x_{n}\right)=\left(I_{n} / I_{N C}\right) \cdot i_{N C}\left(x_{N C}\right) \quad n=1,2, \ldots, N
$$

ELECTRONICS LETTERS 31st March 1988 Vol. 24 No. 7 